DOSSIÊ

\title{
Pensamento Lésbico e Formação da Crítica Queer of Color
}

Caterina A. REA

Universidade da Integração Internacional da Lusofonia Afro-brasileira

Este texto entende refletir sobre as contribuições de autoras lésbicas para a produção da Teoria Queer e, particularmente, da Crítica Queer de cor (Queer of Color Critique). Partindo da consideração de Randy Conner para quem Gloria Anzaldúa foi a primeira a usar o termo queer no contexto da escrita acadêmica, podemos considerar uma outra gênese do Queer, no campo das produções de autoras lésbicas não-brancas. Mostraremos que a crítica Queer of Color tematiza, hoje, a importância de coletivos lésbicos de cor e a maneira em que esses questionam as políticas LGBT mainstream, particularmente, nos países centrais. A chegada da teoria queer para o continente africano, também, revela o protagonismo de mulheres lésbicas acadêmicas e ativistas.

PALAVRAS-CHAVE: Crítica Queer of Color. Interseccionalidade. Pensamento Lésbico. 


\section{Introdução}

Refletir sobre o pensamento lésbico, dar visibilidade e destaque para as escritas de mulheres lésbicas como produções teórico-políticas dignas de atenção acadêmica constitui, com certeza, algo corajoso e inovador, na universidade brasileira, especialmente em uma conjuntura política tão pouco favorável para a afirmação de um pensamento contestador e transgressivo, como o que visa a uma análise crítica e articulada das opressões. O objetivo deste texto é, em particular, refletir sobre as contribuições de pensadoras e ativistas lésbicas não-brancas para a produção e o desenvolvimento da Crítica Queer of Color e da Teoria Queer Africana. Embora estas correntes teórico-políticas sejam irredutíveis ao campo do pensamento prioritariamente centrado na lesbianidade, e que nem todas as suas referências sejam mulheres lésbicas, acreditamos que o aporte destas últimas, de suas experiências e práticas políticas seja decisivo para a produção deste campo.

O debate sobre a introdução do termo queer no contexto acadêmico e, particularmente, sobre a constituição da Crítica Queer of Color revela esta centralidade de um pensamento lésbico. Antes de analisar um tal debate, é preciso apresentar brevemente o que se entende hoje, no contexto feminista e queer transnacional, por Crítica Queer of Color. Na introdução ao volume de 2011, dos Cahiers do CEDREF, dedicado à apresentação de "teorias feministas e queer descoloniais", Paola Bacchetta, Jules Falquet e Norma Alarcón afirmam que teoria e crítica Queer of Color "podem ser definidas como teorias queer que abordam, sem separá-los, o gênero, as sexualidades, o racismo, a colonialidade, o genocídio, a escravidão, a pós-escravidão e a exploração de classe" (2011: 8). As autoras enfatizam a íntima relação entre teorias e críticas Queer of Color e a tradição feminista e afirmam que este campo teórico destaca as "críticas do sexismo em sua inseparabilidade com outras relações de poder. Encontramos feministas de cor que se autoidentificam como queers e queers of color que se apresentam como resolutamente feministas" (BACCHETTA, FALQUET, ALRACÓN, 2011: 9).

A crítica Queer of Color pretende se diferenciar das outras produções queer que poderiam ser definidas como brancas, pois centradas na dissidência sexual e de gênero, conferindo um papel secundário aos outros marcadores sociais. É assim que, como afirmam, mais uma vez, Bacchetta, Falquet e Alarcón, em relação a estas versões 
brancas do queer, "o sujeito queer que elas postulam é sempre primariamente um sujeito dominante no plano da raça, da colonialidade e da classe, ou seja, um sujeito branco de classe média" (2011: 9). Tratase, assim, de vozes radicais no mundo queer internacional, vozes inquietas e insatisfeitas com os rumos elitistas e conformistas das agendas LGBT globais.

\section{Para uma outra genealogia do Queer}

O ponto de vista da teoria Queer of Color poderia nos revelar uma outra genealogia do queer e uma outra história de sua entrada no contexto da produção teórica e acadêmica. "Mesmo que a primeira introdução do termo queer na esfera acadêmica estadunidense seja muitas vezes atribuída ao trabalho de Teresa de Lauretis, que de fato o empregou desde cedo, outras genealogias são possíveis" (BACCHETTA, FALQUET, ALARCÓN, 2011: 10), que remontam até às contribuições de lésbicas de cor, negras e chicanas dos anos 1960 e 1970, como as participantes do Combahee River Collective (Barbara Smith, Audre Lorde, Gloria Hull, Cherlyl Clarke, entre outras), que teve seu Manifesto publicado em 1977, em que se analisava a simultaneidade das opressões; assim como, as autoras da coletânea publicada por Gloria Anzaldúa e Cherrie Moraga, em 1981, This Bridge called my Back e, particularmente, o texto da feminista lésbica chicana, Gloria Anzaldúa, Borderlands/La frontera. The New Mestiza, de 1987. É nesse último texto que Anzaldúa utiliza, pela primeira vez, no contexto acadêmico, o termo queer. Escreve Anzaldúa, no célebre capítulo "La conciencia de la mestiza. Rumo a uma nova consciência”, traduzido pela Revista Estudos Feministas:

Como mestiza, eu não tenho país, minha terra natal me despejou; no entanto, todos os países são meus porque eu sou a irmã ou a amante em potencial de todas as mulheres. (Como uma lésbica não tenho raça, meu próprio povo me rejeita; mas sou de todas as raças porque a queer em mim existe em todas as raças). Sou sem cultura porque, como uma feminista, desafio as crenças culturais/religiosas coletivas de origem masculina dos indo-hispânicos e anglos; entretanto, tenho cultura porque estou participando da criação de uma outra cultura, uma nova história para explicar o mundo e a nossa participação nele, um novo sistema de valores com imagens e símbolos que nos conectam um/a ao/à outro/a e ao planeta. Soy un amasamiento, sou um ato de juntar e unir que não apenas produz uma criatura tanto da luz como da escuridão, mas também uma criatura que questiona as definições de 
luz e de escuro e dá-lhes novos significados (ANZALDÚA 1987/2005: 707-708).

Para Anzaldúa, a condição de queer aproxima-se da de fronteira ou, mais precisamente, @s queers são atravessador@s de fronteiras, ou seja, o que Anzaldúa chamará logo de nepantleras (KEATING, 2006). Fronteira não é simplesmente o que divide e separa duas identidades supostamente fixas e homogêneas, mas é sempre, também, o que une, um ponto de encontro, de passagem, de liminaridade e de transgressão. Como escreve Anzaldúa no primeiro capítulo de Borderlands,

o limite (border) é uma linha divisória, uma faixa estreita ao longo da beira de um precipício. A fronteira (borderlands) é um lugar vago e indeterminado criado pelo resíduo emocional de um limite não natural. Está em um estado constante de transição. Os proibidos e os ilícitos são seus habitantes: los atravesados vivem aqui: os vesgos, os perversos, os queer, os incômodos, os vira-latas, os mestiços, os semimortos, em breve os que atravessam, que transpassam ou que passam os limites do 'normal', (ANZALDÚA, 1987/2007: 25).

Seguindo as reflexões de Randy Conner, podemos, então, traçar a partir de Anzaldúa uma nova genealogia do queer, enraizada na vida e na obra de uma feminista lésbica de cor, que assumiu a própria condição de fronteiriça e de queer (Anzaldúa utiliza mais o termo Nahuatl, patlache, que indica a mulher que ama outra mulher, pois o termo 'lésbica' soa, para ela, como problemático, por conta de sua conotação branca, de classe média e eurocêntrica, pouco apta para a condição das chicanas) ${ }^{1}$. Randy Conner, que foi amigo íntimo de Gloria Anzaldúa, avançou esta tese na Conferência Internacional El Mundo Zurdo, em 2009, em seu paper intitulado "Santa Nepantla. A Borderlands Sutra" (2010). O autor apresenta a obra de Gloria Anzaldúa como o lugar genético da teoria queer, um queer, porém, que funda suas raízes nas culturas indígenas mexicanas, na espiritualidade Náhuatl, mas também na das religiões de matriz africana e do culto dos Orixás. As fronteiras que o queer perpassa e transgride são também as da sexualidade e do gênero, conforme lembra Randy Conner: "o poder espiritual de expressar a queerness

\footnotetext{
${ }^{1}$ Reportamos aqui um breve texto de Anzaldúa, que tiramos da tese de Dahms (2012), onde a própria Anzaldúa reconhece que, para ela, “o termo 'lésbica' es problemón... lésbica é um termo cerebral, branco e de classe média, que representa somente a cultura inglesa dominante, e que é derivado do termo grego Lesbos. Penso as lésbicas como mulheres predominantemente brancas e de classe média, e como um segmento de mulheres de cor que adquiriram o termo por osmose, de forma muito parecida a como as chicanas e as latinas assimilaram a palavra hispanic@”, (ANAZALDÚA, 1998, apud DAHMS, 2012: 6).
} 
reside em seu potencial de liquefazer as fronteiras da sexualidade e do gênero - assim como outras fronteiras - liberando, dessa forma, a psique ou o espírito de papeis opressivos" (CONNER, 1997 apud DAHMS, 2012: 37). Queer, patlache, fronteira, mestiza, nepantla/ nepantleras ${ }^{2}$ são termos e categorias através dos quais Anzaldúa visa a contestar as bicategorizações do pensamento moderno colonial e heteropatriarcal e romper com o pensamento binário. Como escreve Anzaldúa, em Borderlands, "cuando vives en la frontera (...), precursor de uma nova raça/metade e metade, ao mesmo tempo homem e mulher e nem um nem outra/um novo gênero (...) Para sobreviver nas fronteiras/ você precisa viver sin fronteras, ser uma encruzilhada", (ANZALDÚA, 1987/2007: 216-217).

Para Anzaldúa e as demais feministas lésbicas chicanas, a teoria nasce da carne e da experiência imbricada de múltiplas formas de dominação, entre as quais não há possibilidade de estabelecer uma hierarquia. A experiência da lesbianidade, em particular, é o lugar onde amadurece a consciência da opressão, que torna possível uma aproximação entre as "güeras" (claras) e as "prietas". Filha de mãe chicana e de pai anglo-americano, Cherrie Moraga tematiza este aspecto, a partir da análise de sua condição de güera, uma condição que lhe conferia privilégios e uma certa passabilidade. A lesbianidade é, porém, o fator que inverte seu processo de branqueamento, reaproximando-a de sua família chicana. Escreve Cherrie Moraga em um capítulo tocante de This Bridge called my Back (citamos aqui um trecho da versão francesa publicada pelos Cahiers du CEDREF):

Quando, enfim, tomei consciência de minha lesbianidade, vi renascer em mim um laço profundo com minha mãe. É só no momento em que reconheci e enfrentei minha lesbianidade, na minha carne, que tomei consciência de que a opressão sofrida por minha mãe - por ela ser pobre, sem instrução e chicana - suscitava em mim sincera identificação e empatia. É minha lesbianidade que mais me ensinou sobre o silêncio e a opressão e segue constituindo um apelo tangível do fato de que nós não somos seres humanos livres (...). O que estou

\footnotetext{
${ }^{2}$ Como escreve AnaLouise Keating, o termo Nepantla "é uma palavra Nahuatl que significa espaço intermediário (in-between). Anzaldúa adotou este termo e o usou para representar pontos psíquicos/espirituais/materiais de potencial transformação. Nos escritos de Anzaldúa, nepantla representa, ao mesmo tempo, uma extensão e uma elaboração sobre suas teorias da fronteira e o estado Coatlicue (descritos em Borderlands). Como a sua teoria da fronteira, nepantla indica o espaço liminar onde as transformações podem acontecer, e como sua teoria do estado de Coatlicue, nepantla indica espaço/tempo de grande confusão, ansiedade e perda de controle", (KEATING, 2006: 8).
} 
dizendo é que as vantagens de parecer uma menina branca perderam seus charmes a partir do momento em que tomei consciência de que podia ser agredida e receber uma surra, na rua, porque sou sapatão. Se minha irmã recebe uma surra porque é negra, é mais ou menos o mesmo princípio. De qualquer forma, nós somos, ambas, agredidas violentamente, (MORAGA, 1981/2011: 48).

Em um mundo, ao mesmo tempo, sexista, racista e homofóbico, é preciso refletir sobre as raízes da opressão, sem criar hierarquias, nem priorizações.

A experiência e a obra de autoras como Gloria Anzaldúa ou Cherrie Moraga tem um papel central para a elaboração da teoria queer e, particularmente, para a crítica Queer of Color, que contesta o primado do sujeito colonial branco e de classe média, que se tornou central na teoria queer dominante. Segundo esta narrativa contra-hegemônica, ao contrário, a teoria queer tem suas bases nas produções de autor@s nãobranc@s,

mas foi apropriada pelos brancos, particularmente homossexuais homens, que, inicialmente, desenfatizaram ou apagaram a raça como uma categoria interseccional de análise e que depois acrescentaram autor@s/crític@s de cor para apimentar suas antologias (...). Recentemente, no entanto, o campo foi contestado por sua falta de reconhecimento de pessoas Queer of Color e lentamente começou a incorporar um repertório teórico mais diversificado, (DAHMS, 2012; 96-97).

Ao documentar de forma detalhada esta reviravolta teórica operada pela Crítica Queer of Color, Roderick Ferguson enfatiza, em seu livro, Aberrations in Black. Towards a Queer of Color Critique (2004), a importância das organizações feministas negras lésbicas e de sua crítica das políticas de identidade, políticas estas perpetuadas pelos movimentos nacionalistas e anti-imperialistas negros nos Estados Unidos. Ferguson nota como as feministas negras, particularmente as lésbicas, tentaram reformular as noções de cultura e de agencia, desvencilhando-as de uma moral conservadora do heteropatriarcado, que reclama pela normatividade sexual e de gênero. A ação do feminismo das mulheres de cor consiste, assim, no esforço de contestar a normalização desta cultura heteropatriarcal. Escreve Ferguson:

Nos últimos anos da década de '70 e nos anos '80, as lésbicas negras foram, em sua maioria, proeminentes nas críticas à heterossexualidade e ao patriarcado. Em seu trabalho, como ativistas, trabalhadoras 
culturais, críticas e teóricas, as feministas negras lésbicas tentaram arrancar a cultura dos confins normativos do nacionalismo, no momento em que a autoridade da cultura nacionalista estava sendo desafiada no mundo inteiro. Nos termos do feminismo negro, as lésbicas negras foram mais longe em teorizar novamente a cultura de forma que a mesma teria refletido uma ruptura em termos de gênero e de sexualidade com o heteropatriarcado e inspirado práticas e formulações que fossem alternativas ao nacionalismo (...). O feminismo lésbico negro ajudou a tornar a imaginação uma prática social que utilizava as formas sociais precisamente por conta da superposição das exclusões de gênero, sexualidade, classe e raça que constituíam as formas de nacionalismo, (FERGUSON, 2004: 117-118).

Tomando seu distanciamento tanto da identidade nacional ocidental, com sua política racista e colonial, afirmada também pelos movimentos feministas e LGBT brancos e hegemônicos - que chamaríamos, aqui, de femonacionalistas e homonacionalistas - como da identidade nacional reivindicada pelos movimentos negros de libertação, as lésbicas de cor questionam "os limites da identidade subalterna", (FERGUSON, 2004: 129), na qual podem, ao mesmo tempo, estar contidas as marcas da dominação.

A crítica da noção da identidade constitui um tema central do Manifesto elaborado, em 1977, pelo coletivo de mulheres lésbicas negras, Combahee River. A identidade não é definida como algo fixo, homogêneo e naturalizado, mas como algo complexo, multifacetado, dinâmico e plural. As autoras do Coletivo Combahee River se questionam sobre as estratégias políticas a serem implementadas para construir coalisões e alianças transversais, a partir da simultaneidade das opressões por elas vivenciadas. Elas rejeitam, assim, o separatismo lésbico, invocado por muitos grupos de lésbicas brancas, pois este apagaria os outros fatores simultâneos da opressão, como a raça e a classe, mas também contestam o modelo sexista e heterossexista, através do qual a identidade negra é muitas vezes forjada. Escrevem as autoras:

Mesmo sendo feministas e lésbicas, nos solidarizamos com os homens negros progressistas, e não defendemos o fracionamento que as mulheres brancas separatistas reivindicam. A nossa situação como negras exige que nos solidarizemos em torno do fato da raça, solidariedade que, é claro, as mulheres brancas não precisam ter com os homens brancos, a não ser que seja a solidariedade negativa como opressores raciais. Nós lutamos junto com os homens negros contra o racismo, e contra os homens negros contra o sexismo (...). Como já declaramos, rejeitamos a posição do separatismo lésbico, porque não é 
uma análise política ou estratégia viável para nós. Ela abandona pessoas demais, particularmente homens, mulheres e crianças negras. Nós temos muitas críticas e repugnância ao que os homens foram socializados a ser nessa sociedade: o que eles apoiam, como agem, e como eles oprimem. Mas não temos a noção desorientada de que é a sua masculinidade, per se - ou seja, a sua masculinidade biológica que os torna quem eles são. Como negras, achamos qualquer tipo de determinismo biológico uma base particularmente perigosa e reacionária sobre a qual construir uma política. Devemos também questionar se o separatismo lésbico é uma análise política e estratégia adequada e politicamente progressiva até mesmo para as que o praticam, já que ele nega completamente todas as fontes não-sexuais da opressão da mulher, negando os fatos da raça e da classe, (COMBAHEE RIVER, 1977/2013).

Como nota, mais uma vez, Ferguson, a própria constatação da simultaneidade das opressões conduz e favorece a procura e a construção de coalisões mais amplas, que impõem uma crítica aos nacionalismos sexuais.

\section{Pensamento lésbico e leitura interseccional do Queer}

Repensar o queer e a dissidência sexual de forma interseccional e repensar a interseccionalidade em uma perspectiva queer, apontando para suas significações teóricas e suas possibilidades de utilizações políticas e militantes, constitui uma das linhas da crítica Queer of Color. Em particular, a noção de assemblages, elaborada por Jasbir Puar (2007), em relação ao funcionamento do homonacionalismo euroamericano, e as noções de co-formações e co-produções, elaboradas por Paola Bacchetta (2009a; 2009b; 2016), pretendem enfatizar a imbricação e o entrelaçamento entre identidades e dinâmicas de poder. Desta forma, co-formações e co-produções podem ser vistas como "um prolongamento anticolonial, descolonial e anticapitalista da interseccionalidade e de outras teorias feministas, trans e queer, da multiplicidade das relações de poder" (BACCHETTA, 2015: 134).

A análise das contribuições dos coletivos lésbicos de cor para o debate e o ativismo LGBT e Queer é um tema recorrente na crítica Queer of Color. Tais coletivos lésbicos de vários países vêm elaborando análises contundentes sobre as múltiplas facetas do poder, desconstruindo a presunção, difundida nos movimentos LGBT euro-americanos, segundo a qual, os sujeitos racializados seriam geralmente heterossexuais e 
normativos, e que pessoas sexualmente dissidentes seriam homogeneamente brancas, (BACCHETTA, 2016). Paola Bacchetta, uma "sujeita racializada, feminista-lésbica (...) envolvida em grupos e movimentos feministas, lésbicos e Queer of Color" (BACCHETTA, 2016: 265), retrata, por exemplo, em vários textos, as estratégias de grupos lésbicos na França, nos Estados Unidos e na Índia, países pelos quais ela transita (2009a; 2009b; 2016). In "QTPOC Critiques of Post-raciality, Segregationality, Coloniality and Capitalism in France" (2016), esta autora traça a história dos movimentos feministas de cor e grupos radicais de pessoas queer e trans of color, especialmente os de lésbicas, na França, apontando para a diferença de estratégias e de formas de agências por elas utilizadas para enfrentar "o conjunto de relações de poder que se constituem mutuamente (co-constitutive)" (BACCHETTA, 2016: 278). Assim, em suas teorizações, essas mulheres, continua Paola Bacchetta, "colocam em evidência as maneiras em que as múltiplas relações de poder são constitutivas umas das outras e como operam inseparavelmente", (BACCHETTA, 2016: 264). Entre tais estratégias de enfrentamento e de resistência, Bacchetta destaca a posição de lésbicas muçulmanas que usam o hijab, no contexto dos protestos contra a lei anti-véu, em 2004, na França. Com sua postura, elas querem perturbar o olhar orientalista, racista e colonial do femonacionalismo e do homonacionalismo franceses, que as enxerga como mulheres desempoderadas e submissas aos homens de suas comunidades. Como escreve Bacchetta, comentando os acontecimentos de 2004:

O véu, com certeza, tem diferentes significados contextuais para aquelas que o portam e para os públicos que o espectacularizam. Eles variam do significado religioso, ao social e ao político. Aqui, vou me ocupar, em particular, das lésbicas veladas, em um contexto em que elas se opõem diretamente a uma lei que as deslegitima e deslegitima sua própria relação com sua religião. Um ponto importante, as lésbicas que usam véu não se manifestam (out) enquanto lésbicas. Desta forma, esta jogada calculada, entre outras coisas, driblou sua fetichização, pelo olhar colonial-racista, (BACCHETTA, 2016: 272).

As análises Queer of Color vêm, repetidamente, criticando a imposição de uma epistemologia única da sexualidade, supostamente universal, mas, de fato, baseada na imposição do modelo ocidental. Tais análises apontam para a existência de diferentes maneiras de viver a própria sexualidade dissidente, dando lugar a uma epistemologia plural da sexualidade, que não necessariamente passaria pelo momento central do coming out e da visibilidade. Nesse sentido, entendemos as reflexões 
de Bacchetta sobre a atitude das lésbicas veladas, nas manifestações parisienses, para quem não se tratava de "sair do armário", segundo uma expressão comum para as lésbicas ocidentais: muitas dentre elas, ao contrário,

colocam em questão, de maneira radical, esta interpretação da saída do armário, elas veem nisso um avanço enganador, uma modalidade voyeurista paradoxal que correria o risco de tornar ainda mais invisíveis e vulneráveis as lésbicas de cor. No momento atual, no quadro de inteligibilidade franco-francesa, o termo totalizante 'lésbica' age ao mesmo tempo apagando as origens étnicas e tornando-as hipervisíveis. Este fenômeno é produzido através da formulação do postulado de um sujeito queer universal, ao qual nenhuma lésbica de cor pode se identificar, (BACCHETTA, 2009b: 9).

Apesar de perturbadora da experiência e da epistemologia da homossexualidade ocidental, esta posição é, em grande parte, reivindicada pel@s queer de cor, na tentativa de desconstruir a imposição de um modo único, supostamente universal, de vivência da homossexualidade, que é veiculado pelo modelo euro-americano. Disso advém a ressignificação do próprio termo queer para além da dissidência sexual, onde este termo passa a se opor não somente à heterossexualidade, mas sobretudo a formações homonormativas, homonacionalistas e homoneoliberais (EL-TAYEB, 2011). A Crítica Queer of Color problematiza a narrativa do progresso em matéria de direitos humanos e sexuais como sendo própria do Ocidente e a ideia segundo a qual este seria o lugar mais avançado para o respeito às mulheres e às pessoas LGBT. Esta narrativa apaga e invisibiliza a realidade do racismo e as desigualdades sociais que estruturam o mundo ocidental, assim como a história colonial e suas heranças. Fatima ElTayeb aponta que estes ganhos "não são colocados em um quadro maior como parte de um avanço na direção da igualdade e da justiça social e não se tem nenhum reconhecimento da antiga e nova violência que acompanha o multiculturalismo neoliberal, que oferece inclusão a certos grupos anteriormente excluídos, na medida em que estes cabem no modelo do cidadão consumidor”, (EL-TAYEB, 2016: 154). A Crítica Queer of Color contesta, assim, a reciclagem da queerness (branca e burguesa) pelo projeto neoliberal que, impõe a exclusão de outros sujeitos e de outros corpos com ele julgados incompatíveis. Uma tal lógica é inaceitável para quem enfrenta a dominação de maneira interseccional, como um conjunto de múltiplas dinâmicas de poder, pois seria impossível lutar contra a homofobia, sem enfrentar, ao mesmo 
tempo, o racismo, o sexismo e as desigualdades econômicas e de classe (El-TAYEB, 2016).

A retórica femo/homonacionalista e homonormativa das comunidades LGBT brancas ocidentais oculta a pluralidade das opressões, demonizando e afastando os grupos racializados (populações oriundas de antigas e novas diásporas, imigrantes que provêm do Leste e do Sul global) que, nesta lógica, são sempre suspeitos de homofobia, de lesbofobia, de misoginia e de sexismo. Esta retórica binária é a mesma que justifica intervenções 'humanitárias' nos países do Sul Global, muitas vezes, unicamente, animadas por um espírito salvacionista e pelo "interesse de procurar a homofobia em todo o Sul global" (EKINE, 2013: 85). Como destacam as curadoras da primeira coletânea queer africana, estas intervenções são, na maioria dos casos, vivenciadas pelos grupos LGBTIQ nos contextos locais como uma indevida ingerência das nações neocoloniais, que pretendem impor suas agendas políticas, embebidas de neoliberalismo, aos movimentos do Sul Global (EKINE; ABBAS, 2013).

Olhando para as produções do campo Queer africano, notamos, tanto no caso do Queer African Reader (2013), como da coletânea Reclaiming Afrikan (2014), o protagonismo evidente de mulheres lésbicas. Ambas estas edições, pioneiras na divulgação da crítica queer africana, são encabeçadas por mulheres lésbicas, editoras e coordenadoras das coletâneas. Como no caso da crítica Queer of Color, estas contribuições visam a situar a queerness no contexto africano e no das lutas antirracistas, anticoloniais e em prol da justiça econômica e social, com as quais as reivindicações da dissidência sexual precisam se aliar. Como diz a militante lésbica nigeriana, Sokari Ekine, @s "african@s queer não são somente queer, são pessoas que vivem suas vidas como quaisquer outras, e como tal, nossa luta necessita se alinhar com outros movimentos de justiça social, como os das mulheres rurais, dos moradores de cabanas, da mudança climática, dos direitos à terra e demais", (EKINE, 2013: 89). Nesta direção, a reflexão sobre a condição lésbica se apresenta como inseparável de uma reflexão sobre negritude e africanidade. Isso aparece bem explícito nos textos da acadêmica e militante sul-africana, Zethu Matebeni, cujos textos, nas duas coletâneas, denunciam as violências perpetuadas, na África do Sul, contras lésbicas negras e de camadas populares (2012 e 2014). A denúncia de tais violências deve envolver um olhar interseccional, capaz de levar em conta o caráter complexo e plural de suas identidades e de suas 
experiências. Como afirma Zethu Matebeni, "apesar das leis progressistas que defendem os direitos gays, as lésbicas negras, na África do Sul, vivem, em muitas e violentas maneiras, sob duras condições e tentativas de eliminar suas subjetividades sexuais" (MATEBENI, 2013: 344). Isso implica na prática difundida de "estupros corretivos e curativos" (MATEBENI, 2013: 344), um termo que precisa, porém, ser analisado com mais cuidado, segundo esta autora. De fato, continua a mesma,

se trata de uma posição complexa e difícil para tomar, pois, de um lado, (...) as lésbicas são atacadas por conta de sua contestação, percebida ou real, da ordem sexual e de gênero. Por outro lado, enquadrando as lésbicas negras como vítimas específicas de uma forma de estupro, a linguagem do estupro corretivo situa as lésbicas negras dos bairros populares da África do Sul fora de lutas mais amplas pela justiça social em termos de gênero, classe, sexualidade e raça, no contexto sul-africano, (MATEBENI, 2013: 344).

Neste sentido, a condição de violência sofrida pelas lésbicas negras sul-africanas não se deixa encaixar na única lógica do estupro corretivo, que apaga e invisibiliza as outras formas simultâneas e correlativas de relações de poder que as oprimem.

Desta forma, para a perspectiva Queer of Color e queer africana, que fazem uma leitura intersecional e interseccionada da dissidência sexual, as produções das lésbicas não podem se limitar a uma reflexão unicamente centrada na lesbianidade, como uma condição transgressiva em relação ao hetero-patriarcado, pois suas vidas se inscrevem em coformações e co-produções complexas de relações de poder. Enfatizar a importância das lésbicas de cor e sua construção para o debate queer contemporâneo implica o fato de levar em conta a "diversidade lésbica", (SABREEN, MORUNI; ARIA, 2016: 143). Esta última entende trazer à tona a experiência de identidades plurais e da "inseparabilidade de gênero, sexualidade, racismo, classes, escravidão e suas consequências, colonialismo e pós-colonialismo", (SABREEN, MORUNI, ARIA, 2016: 143-144).

\section{Conclusão}

Neste texto, argumentamos amplamente que as produções de mulheres lésbicas de cor (chicanas e negras, ou africanas) foram de importância imprescindível para a criação e o desenvolvimento do 
campo prático e teórico Queer e para o que chamamos, hoje, de segunda onda Queer, ou seja, a Crítica Queer of Color. De Gloria Anzaldúa e Cherrie Moraga, passando pelas lésbicas negras do coletivo Combahee River, estas autoras nos convidam a romper as fronteiras rígidas do pensamento identitário e testemunham, em seus corpos e sua carne, a impossibilidade de escolher uma só de suas identidades. Neste sentido, tratamos de retraçar uma genealogia diferente para a teoria Queer, colocando-a, desde o começo, no berço das comunidades de cor e convidando estas últimas, nas palavras de Anzaldúa, a "reconhecer as contribuições artísticas e políticas dos seus queers. Povo escute o que sua jotería está dizendo", (ANZALDÚA, 2005: 712).

O desafio inaugurado por Anzaldúa e seu pensamento da liminaridade e do cruzamento, encarnado pelas neplanteras, se expande e alimenta novas epistemologias e novas estratégias de resistência por parte de pessoas de cor (BACCHETTA, 2010), particularmente lésbicas, em diferentes contextos transnacionais. Como no caso da fronteira ou da condição mestiça, para Anzaldúa, se trata de repensar a noção de interseccionalidade e de enfrentar a realidade das formas simultâneas e imbricadas de dominação. Hoje, mais do que antes, no contexto do neoliberalismo triunfante, é preciso enfrentar o "demônio de muitas cabeças da opressão" (ANZALDÚA; MORAGA, 1981: 195) pois, como diz Fatima El-Tayeb, "todos estes sistemas interseccionais devem ser mudados, antes de atender a liberação, se entendemos por liberação a ausência de qualquer sistema de carência no qual a privação de direitos humanos básicos não é uma exceção, mas a mesma lógica ao redor da qual o sistema é construído", (EL-TAYEB, 2016: 163). Neste sentido, para as lésbicas não-brancas e para a crítica Queer of Color, a posição queer precisa retomar a radicalidade e a força de uma postura política das margens, e seu papel de uma voz contestadora do conformismo imperante imposto pelo modelo capitalista neoliberal.

\section{Referências}

ANZALDÚA, Gloria. Borderlands/La Frontera. The New Mestiza. San Francisco: Aunt Lute Book

ANZALDÚA, Gloria; MORAGA, Cherrie. This Bridge called my Back. New York: Kitchen Table, 1983. 
BACCHETTA, Paola; FALQUET, Jules; ALARCÓN, Norma. Théories féministes et Queer décoloniales: interventions Chicanas et Latinas états-uniennes. Cahiers du CEDREF, pp. 7-40, 2011.

BACCHETTA, Paola. Co-formações/co-produções: considerações sobre poder, sujeitos subalternos, movimentos sociais e resistência. In: TORNQUIST, Carmen Susana e alt. Leituras de resistência: corpo, violência, poder. Florianópolis: Editora Mulheres, 2009a.

BACCHETTA, Paola. Co-formations: des spatialités des résistences décoloniales chez les lesbiennes of color em France. Genre, Sexualité \& Société, 2009b. Disponíble em: http://journals.openedition.org/gss/810 visto em 26/02/2018.

BACCHETTA, Paola. Transnational Borderlands: Gloria Anzaldúa's epistemologies of resistence and lesbians of color in Paris. In: CANTÚ, Norma; GUTIÉRREZ, Christina; ALARCÓN, Norma; URQUIJO-RUIZ, Rita. El Mundo Zurdo. Selected Works from the meetings of the Society for Study of Gloria Anzaldúa, 2007-2009. San Francisco: Aunt Lute Books, 2010, pp. 109-126.

BACCHETTA, Paola. Décoloniser le féminisme: intersectionnalité, assemblages, co-formations, co-productions. Cahiers du CEDREF, pp. 125-137, 2015.

BACCHETTA, Paola. QTPOC Critiques of Post-raciality, Segregationality, Coloniality and Capitalism in France. In: BAKSHI, Sandeep; JIVRAJ, Suhraiya; POSOCCO, Silvia. Decolonizing sexualities. Transnational perspectives, Critical Interventions, 2016, pp. 264-281.

COMBAHEE RIVER COLLECTIVE, Manifesto (1977). Tradução portuguesa, 2013, disponível e m: http:/ / rodrigosilvadoo.blogspot.com.br/2013/11/declaracao-do-coletivocombahee-river.html visto em 26/02/2018.

CONNER, Randy P. Santa Nepantla: a Borderlands sutra plenary speech. In: CANTÚ, Norma; GUTIÉRREZ, Christina; ALARCÓN, Norma; URQUIJO-RUIZ, Rita. El Mundo Zurdo. Selected Works from the meetings of the Society for Study of Gloria Anzaldúa, 2007-2009. San Francisco: Aunt Lute Books, 2010, pp. 177-202. 
DAHMS, Elizabeth Anne. The life and work of Gloria Anzaldúa: ain intelectual biography. Dissertation, 2012. Disponível em: https:// u kn o w l e d g e . u k y. ed u / c gi / vi e w c o n t e n t . c gi ? article $=1005 \&$ context=hisp_etds Visto em: 18/02/2018.

EKINE, Sokari. Contesting narratives of Queer Africa. In: EKINE, Sokari; ABBAS, Hakima. Queer African Reader. Dakar, Nairobi, Oxford: Pambazuka Press, 2013, pp. 78-91.

EKINE, Sokari; ABBAS, Hakima. Queer African Reader. Dakar, Nairobi, Oxford: Pambazuka Press, 2013.

EL-TAYEB, Fatima. European Others. Queering Ethnicity in Postnational Europe. Minneapolis/London: University of Minnesota Press, 2011.

EL-TAYEB, Fatima. Lesbian of Colour Activism and Racist Violence in Contemporary Europe. In: BAKSHI, Sandeep; JIVRAJ, Suhraiya; POSOCCO,Silvia. Decolonizing sexualities. Transnational perspectives, Critical Interventions, 2016, pp. 154-169.

FERGUSON, Roderik. Aberrations in Black. Towards a Queer of Color Critique. Minneapolis/London: University of Minnesota Press, 2004.

KEATING, AnaLouise. From borderlands and new Mestizas to Nepantlas and Nepantleras: Anzaldúan theories for social change. Human Architecture: Journal of Sociology and Self-Knowledge, vol. 4, n.3, 2006, pp. 5-16.

LESBIENNES OF COLOR (SABREEN, MORUNI; ARIA. Decolonial Activism in White French Feminist Land. In: BAKSHI, Sandeep; JIVRAJ, Suhraiya; POSOCCO,Silvia. Decolonizing sexualities. Transnational perspectives, Critical Interventions, 2016, pp. 141-153.

MATEBENI, Zethu. Deconstructing violence towards black lesbians in South Africa. In: EKINE, Sokari; ABBAS, Hakima. Queer African Reader. Dakar, Nairobi, Oxford: Pambazuka Press, 2013, pp. 343-353.

MATEBENI, Zethu. How not to write about queer South Africa. In: MATEBENI, Zethu (org.). Reclaiming Afrikan. Queer perspectives on sexual and gender identities. Athlone:Modjaji Books, 2014, pp. 57-59. 
MORAGA, Cherrie. La Guera. Cahiers du CEDREF, pp. 45-56, 2011.

PUAR, Jasbir. Terrorist Assemblages. Homonationalism in Queer Times. Durham/London: Duke University Press, 2007. 


\title{
Pensée lesbienne et formation de la critique Queer of Color
}

\begin{abstract}
Ce texte prétend réfléchir sur la contribution d'auteures lesbiennes pour la production de la théorie Queer et, particulièrement, de la critique Queer of Color. En partant de la considération de Randy Conner, pour qui Gloria Anzaldúa a été la première à utiliser le terme queer dans le contexte académique, on peut considérer une genèse autre du queer, a partir du champ de production d'auteures lesbiennes non blanches. Nous montrerons que la critique Queer of Color thématise, aujourd'hui, l'importance de collectifs lesbiens de couleur et la manière par laquelle ceux-ci questionnent les politiques LGBT mainstream, surtout, dans les pays centraux. L'arrivée de la théorie queer au continent africain, aussi, manifeste le protagonisme des femmes lesbiennes, académiciennes et activistes.
\end{abstract}

KEYWORDS: Critique Queer of Color. Intersectionnalité. Pensée Lesbienne.

Caterina A. REA

Caterina A. Rea é professora Adj. C I da Universidade da Integração da Lusofonia Afro-brasileira (UNILAB)/Campus dos Malês (Bahia). É doutora em

Filosofia pela Université Catholique de Louvain (Bélgica) e, atualmente, coordenadora do Grupo de Pesquisa Pós-colonialidade, Feminismos e Epistemologias Anti-hegemônicas/EMPOS/UNILAB. 